\title{
Screening for FXTAS
}

European Journal of Human Genetics (2005) 13, 2-3. doi:10.1038/sj.ejhg.5201318

Published online 20 October 2004

The fragile $X$ premutation is an unstable stretch of CGG repeats $(55-200)$ in the $5^{\prime}$ UTR of the fragile $-X$ mental retardation 1 gene (FMR1), (for review, see Hagerman and Hagerman $^{1}$ ). The premutation can expand to a full mutation (fragile $X$ syndrome) in the subsequent generation. The American College of Medical Genetics has set the lower bound of the premutation at 55 CGG repeats. Others have, however, suggested different lower limits. The carriers of premutation alleles were initially assumed to be asymptomatic. This assumption was challenged when premature ovarian failure was first reported in 1991 and subsequently confirmed by other investigators. ${ }^{2-4}$ Another form of clinical involvement has recently been identified among older male carriers of the FMR1 premutation. ${ }^{5}$ The symptoms consist of progressive intention tremor, gait ataxia, and Parkinsonism. Associated features include autonomic dysfunction, peripheral neuropathy, and cognitive difficulties such as memory loss and executive function deficit. Hyperintensities in the middle cerebellar peduncles on T2-weighted MRI images represent a major criterion for the diagnosis of 'Definite' fragile X-associated tremor ataxia syndrome (FXTAS). ${ }^{6}$

Our knowledge of FXTAS is mainly based on individuals ascertained through families with a known proband affected with fragile X syndrome. The premutation carrier affected with FXTAS is typically the grandfather of the proband. In these cases, the distribution of premutation alleles among transmitting males is likely to be shifted towards larger CGG repeats since larger alleles are more likely to give rise to a full mutation (fragile $\mathrm{X}$ proband). This recruitment method raises several important issues: one being whether the clinical presentation or the penetrance of the disorder is different in males with lower CGG repeats and no family history of fragile $X$. The projected prevalence estimates for FXTAS in the general population were based on the observed penetrance of FXTAS in fragile $X$ families $^{7}$ and the observed prevalence of the premutation in males of the general population $(1 / 810) .^{8}$

In this month's issue of the European Journal of Human Genetics, the report by Van Esch et al ${ }^{9}$ examined the frequency of expanded FMR1 alleles in 122 patients 50 years of age and older referred to their neurology clinic for ataxia. The main spinocerebellar ataxia genes had been previously ruled out. These individuals did not have a family history of fragile $\mathrm{X}$ syndrome. In their group of patients, they found five individuals with an FMR1 premutation, confirming the initial figures of 3/59 males reported by Macpherson et al $^{10}$ and 2/28 males aged $>50$ years referred for SCA testing reported by Di Maria et al. ${ }^{11}$ The lower prevalence detected by Milunsky and Maher ${ }^{12}$ of $1 / 167$ cases could be due to a difference in ascertainment. These figures are in contrast with the absence of FMR1 premutation alleles in groups of patient with essential tremor. $^{13,14}$

One of the main strengths of the study by Van Esch et al is that the MRIs were available for the male carriers of the premutation. This allowed the authors to diagnose four out of five cases with 'definite FXTAS' according to the presence of the hyperintense signals in the middle cerebellar peduncles. ${ }^{6}$ This was not the case in previous screening reports. The main limitation of these three retrospective studies is the lack of information on the patient population. It is therefore difficult to interpret the different prevalence figures.

To date, FXTAS has only been identified within the premutation range. The Hagermans and collaborators have hypothesized that the elevated levels of abnormal FMR1 RNA, observed in the majority of premutation carriers, could be toxic to the nervous system. They proposed an RNA 'toxic gain of function' model, by analogy with myotonic dystrophy, to account for the neuropathology of FXTAS (see Hagerman and Hagerman ${ }^{1}$ and references therein). This hypothesis was supported by a knock in mouse model (for inclusion formation) and a Drosophila model, with both model systems expressing premutation length CGG repeats (for review, see Oostra and Willemsen). ${ }^{15}$ The mouse and fly models both demonstrated neuronal, intranuclear inclusions, characteristic of FXTAS, and in the case of the fly model, additional signs of neurodegeneration.

Interestingly, the allele sizes reported by Van Esch et al $(80,82,84,91,111)$ and Di Maria et $a^{11}(86,87)$ are identical to those reported in the fragile $X$ 'family-based' studies. This could suggest that shorter CGG repeats $(<80$ CGG) are less toxic, leading to a milder phenotype and a lower penetrance of the clinical manifestation. In other words, there could be a correlation between the CGG repeat number (or CGG molarity) and the severity of the phenotype, although this has not yet been reported. There 
is also a concern that the grey zone may have some mild toxicity. This is an important issue because lower bound premutation and grey zone alleles are more frequent in the general population.

One of the lessons we can retain from FXTAS is the challenge of identifying and characterizing low-penetrance genetic disorders or genetic risk factors predisposing to common clinical symptoms. The FMR1 gene was discovered in 1991 and it took 10 years of drawing pedigrees before one would associate the symptoms of FXTAS to the FMR1 premutation. Although more studies are still warranted, the report by Van Esch et al will contribute to establish guidelines for FMR1 testing in neurology clinics.

Sébastien Jacquemont ${ }^{*, 1}$

${ }^{1}$ Service de génétique médicale, CHU de Nantes, France

*Correspondence: Dr S Jacquemont, Service de génétique médicale, CHU de Nantes, France.

E-mail: sebastien.jacquemont@chu-nantes.fr

1 Hagerman PJ, Hagerman RJ: The fragile-X premutation: a maturing perspective. Am J Hum Genet 2004; 74: 805-816.

2 Cronister A, Schreiner R, Wittenberger et al: Heterozygous fragile $\mathrm{X}$ female: historical, physical, cognitive, and cytogenetic features. Am J Med Genet 1991; 38: 269-274.

3 Schwartz CE, Dean J, Howard-Peebles PN: Obstetrical and gynecological complications in fragile $\mathrm{X}$ carriers: a multicenter study. Am J Med Genet 1994; 51: 400-402.

4 Muray A, Webb J, Grimley S et al: Studies of FRAXA and FRAXE in women with premature ovarian failure. J Med Genet 1998; 35: $637-640$.
5 Hagerman RJ, Leehey M, Heinrichs W et al: Intention tremor, parkinsonism, and generalized brain atrophy in male carriers of fragile X. Neurology 2001; 57: 127-130.

6 Jacquemont S, Hagerman RJ, Leehey $M$ et al: Fragile $\mathrm{X}$ premutation tremor/ataxia syndrome: molecular, clinical, and neuroimaging correlates. Am J Hum Genet 2003; 72: 869-878.

7 Jacquemont S, Hagerman RJ, Leehey MA et al: Penetrance of the fragile $\mathrm{X}$-associated tremor/ataxia syndrome in a premutation carrier population. JAMA 2004; 291: 460-469.

8 Dombrowski C, Levesque S, Morel ML, Rouillard P, Morgan K, Rousseau F: Premutation and intermediate-size FMR1 alleles in 10572 males from the general population: loss of an AGG interruption is a late event in the generation of fragile $\mathrm{X}$ syndrome alleles. Hum Mol Genet 2002; 11: 371-378.

9 Van Esch H, Dom R, Bex D et al: Screening for FMR-1 premutations in 122 older Flemish males presenting with ataxia. Eur J Hum Genet 2004; 12.

10 Macpherson J, Waghorn A, Hammans S, Jacobs P: Observation of an excess of fragile- $X$ premutations in a population of males referred with spinocerebellar ataxia. Hum Genet 2003; 112: 619620.

11 Di Maria E, Grasso M, Pigullo S et al: Further evidence that a tremor ataxia syndrome may occur in fragile $\mathrm{X}$ premutation carriers; Abstract presented at the American Society of Human Genetics, 53rd annual meeting, Los Angeles, November 4-8: 2003.

12 Milunsky JM, Maher TA: Fragile $\mathrm{X}$ carrier screening and spinocerebellar ataxiain older males. Am J Med Genet 2004; 125A: 320.

13 Arocena DG, Louis ED, Tassone F et al: Screen for expanded FMR1 alleles in patients with essential tremor. Mov Disord 2004; 19: 930-947.

14 Tan EK, Zhao Y, Puong KY et al: Fragile X premutation alleles in SCA, ET, and parkinsonism in an Asian cohort. Neurology 2004; 63: $362-363$

15 Oostra BA, Willemsen R: A fragile balance: FMR1 expression levels. Hum Mol Genet 2003; 12: R249-R257. 